\title{
Benford's Law in Forensic Analysis of Income Statements of Economic Entities in Bosnia and Herzegovina
}

\section{Ševala Isaković-Kaplan}

School of Economics and Business, University of Sarajevo, Bosnia and Herzegovina

sevala.isakovic-kaplan@efsa.unsa.ba

\section{Lejla Demirović}

School of Economics and Business, University of Sarajevo, Bosnia and Herzegovina

lejla.demirovic@efsa.unsa.ba

\section{Mahir Proho}

AS Holding, Sarajevo, Bosnia and Herzegovina

mahirproho@gmail.com
CroEconSur

Vol. 23

No. 1

June 2021

pp. 31-61

Received: January 2, 2021

Accepted: April 1, 2021

Research Article

doi:10.15179/ces.23.1.2

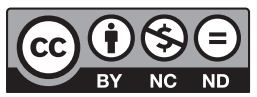

\section{Abstract}

The objective of preparing and presenting financial statements is to provide information about the financial position and performance of an entity, which is useful to a wide range of users of financial statements for business decisions. If information presented in the financial statements is not full disclosure and/or is incorrect, the presented image of the business entity will be wrong, as well as business decisions made on the basis of such financial statements. Unfortunately, many entities knowingly manipulate revenues and expenses to manage earnings in a way that suits the entity management. Detecting frauds in financial statements is the primary task of forensic accountants. This paper analyzes the possibilities of applying Benford's law in the forensic analysis of income statements of economic entities in Bosnia and Herzegovina, to detect possible earnings manipulation. 
The results of the research confirm that the positions of revenues and expenses in the income statements of economic entities in Bosnia and Herzegovina generally follow Benford's law, but also stress the need to increase attention and conduct additional forensic investigations for certain items as indicators of financial statement manipulation.

Keywords: Benford's law, the first digit phenomenon, financial statement fraud, fraud indicator, forensic accounting

JEL classification: M41, M42, K13

\section{Introduction}

The identification of various irregularities in the financial statements of economic entities and mapping the area of possible fraud in the financial statements are difficult tasks that stand before forensic accountants. Namely, frauds in financial statements are mostly cleverly hidden and supported through the creation of false documentation or alteration, concealment, and/or destruction of existing documentation, all for the purpose of supporting fictitious events and/or hiding evidence of occurred and unreported events in the accounting records of economic entities. Unlike a case of serious crime, for example robbery or murder, where visible evidence exists and testifies to the committed crimes, frauds in financial statements are rarely observed - we can only identify the so-called financial statement fraud indicators (Zimbelman, Albrecht, Albrecht, \& Albrecht, 2012).

Therefore, forensic accounting constantly and intensively looks for new techniques for early and easier detection of irregularities (errors or frauds) in financial statements. The development of information technology has enabled forensic accountants to apply a broader set of tools for easier identification of illogical transactions and the mapping of risky areas of financial reporting, among which Benford's law stands out. Research of various accounting data has confirmed that many positions of financial statements follow the distribution of the probability 
of occurrence of the first digit in accordance with the first digit phenomenon, and therefore the application of Benford's law in the forensic analysis of financial statements is possible and generally acceptable (Nigrini \& Mittermaier, 1997; Nigrini, 1999; Tapp \& Burg, 2001).

The story about the first digit phenomenon began in 1881, when there were no calculators and when the American astronomer Simon Newcomb noticed that the first pages of books with logarithmic tables were used the most, and the last pages the least. This implied that the numbers starting with the digit 1 were the most frequently used (for different purposes), i.e., had the most probability to be used. However, after almost 60 years, Frank Benford laid the mathematical foundation for this phenomenon and this law became known in the literature as Benford's law.

In the present paper, data about published revenues and expenses, based on the financial statements of economic entities from Bosnia and Herzegovina $(\mathrm{BiH})$ listed on the Sarajevo Stock Exchange, are collected and analyzed, to test for compliance with Benford's law. The aim of this paper is to investigate whether the revenue and expense items presented in the financial statements of entities in $\mathrm{BiH}$ follow Benford's law, and consequently to identify possible deviations of accounting data from expected values according to Benford's law, potentially pointing to suspicious earnings management in entities in $\mathrm{BiH}$.

The research hypotheses are:

H1: The items of revenues and expenses shown in the income statements of economic entities in BiH follow Benford's law.

H2: There is no statistically significant difference in the distribution of the first digit between the items of revenues and expenses shown in the income statements of economic entities in BiH. 


\section{Literature Review: Benford's Law in Accounting and Auditing}

The first person who noticed that numbers do not appear in equal frequency was Newcomb (1881), but he could not provide additional evidence of this fact. Actually, after almost 60 years, the first serious research about the first digit phenomenon was done by Frank Benford (1938), who collected more than 20,000 data observations from various collections such as river lengths, atomic weights of elements, and presented numbers in journals. In all these different data collections, it was observed that the number 1 appears as the first digit in more than 30 percent of cases. Because of the discovery and the formulation of this mathematical rule, this phenomenon became known as Benford's law.

The development of information technologies has enabled easier digital data analysis and a more comprehensive application of a set of tools for detecting various anomalies in numbers. One of the pioneers in the application of Benford's law in accounting and auditing was Charles Carslaw (1988), who conducted a complete forensic analysis of anomalies in revenues, on a sample of entities from New Zealand and the United States. Carslaw pointed out in his research that entities that presented a positive financial result in their financial statements showed a higher (lower) frequency of zero (nine) as the second digit in the amount of profit, which indicates possible earnings manipulation in the entities covered by the research. Thomas (1989) also used Benford's law to analyze earnings management in entities, and discovered the reverse behavior pattern, i.e., an excess of nines and a lack of zeros in entities that show a negative financial result in their reports.

Boyle (1994) showed that data collections follow Benford's law even when the elements are the result of random variables which are multiplied or divided. This implies that accounting data, which are often the result of mathematical operations, follow Benford's law. A simple example of this can be revenues of sold products, which are the result of multiplying the sold product quantity with the 
product price, as well as numerous categories of expenditures, costs, or expenses, such as material costs, salary costs, etc. In addition to previous research, Hill (1995) set up mathematical proof for Benford's law and tested its application on the stock market.

Nigrini and Mittermaier (1997) presented a procedure for applying Benford's law to help detect unusual patterns in accounting data. Accordingly, it is very possible that an individual, with the purpose of manipulation of financial statements, will enter numbers more than once, the same or similar ones, which deviate from the natural distribution of numbers according to Benford. The observed deviations can be an indicator that the financial statements were fabricated.

Nigrini (1999) highlighted several areas for the application of Benford's law in digital analysis for audit purposes, and these areas are payment data, revenues, estimates, inventories, and customer returns. Tapp and Burg (2001) state that Benford's law can also be applied in the area of detecting frauds in supplier transactions and detecting fictitious suppliers.

However, prudence is needed during the application of Benford's law in the area of accounting and auditing because it was not designated for all data collections (Coderre, 2000). Thus, Durtschi, Hillison, and Pacini (2004) specifically point out that Benford's law is not useful in analyzing data composed of numbers defined according to a particular sequence (e.g., phone numbers), numbers assigned under the influence of people's mindset (e.g., psychologically determined prices that usually end at 9.99), or accounts with a defined maximum and minimum balance value (e.g., cash account in certain entities).

In the analysis of deviations from Benford's law, in addition to the analysis of the first digit, an analysis of the first two digits can also be used. However, analyses of the first two digits can mostly be used in an indirect way, to indicate which numerical groups were "overused" (Lolbert, 2006). 
Also, it is important to emphasize that Benford's law is used by forensic accountants as part of preliminary analytical procedures and it is only a signal of certain illogicality in the presented financial statements of the entity. In addition, symptoms of fraud in entities can be: various accounting anomalies, i.e., irregularities in the documentation serving as a basis for posting, irregularities in postings in the books, discrepancies between the values of postings in the journal and general ledger according to different verification criteria, various analytical anomalies among financial positions presented in financial statements, weaknesses of the entity's internal control system, extravagant lifestyle and unusual behaviour of certain persons, and various tips and complaints about the entity. Forensic accountants should carefully investigate each registered symptom of fraud with an aim of seeking evidence, which will confirm/reject the existence of fraud in the entity and in its financial statements.

Papers of several authors from the region (Milojević, Terzić, \& Marjanović, 2014; Papić, Vudrić, \& Jerin, 2017; Kovačić \& Mateješ, 2018; Bartulović \& Mitrović, 2020) highlight the relevance of research on the application of Benford's law with the aim of detecting potential earnings manipulation in business entities.

\section{Conceptual Research Framework: Benford's Law and Statistical Tests}

Benford's law was based on a logarithmic distribution, and the general formula for the first digit is:

$P(d)=\log \left(1+\frac{1}{d}\right)$,

where $\mathrm{d} \in(1,2,3 \ldots 9)$.

Thus, the probability of occurrence of the digit 1 as the leading/first digit in data is calculated as:

$P(1)=\log \left(1+\frac{1}{1}\right)=\log (1+1)=\log (2)=0.3010$. 
Actually, the probability of occurrence of the digit 1 is 30.10 percent. In the same way, we calculate the probabilities of occurrence of the digits from 2 to 9 as the first digit. The probability of the appearance of the first digit can be shown in a table as follows.

Table 1: Probability of Occurrence of the First Digit

\begin{tabular}{|c|c|c|c|c|c|c|c|c|c|}
\hline Digit & 1 & 2 & 3 & 4 & 5 & 6 & 7 & 8 & 9 \\
\hline Probability in \% & 30.10 & 17.60 & 12.49 & 9.69 & 7.91 & 6.69 & 5.79 & 5.11 & 4.57 \\
\hline
\end{tabular}

Source: Benford (1938).

Using the same formula, the probability of occurrence of the first two digits can be calculated, where $\mathrm{d} \in(10,11,13 \ldots 99)$.

For the purpose of testing whether a given data distribution follows Benford's first digit distribution, the research conceptual framework uses the following tests:

- Z-test

- MAD

- chi-square

- $\mathrm{K}-\mathrm{S}$ test.

The Z-test is used to assess whether the actual portion of digits varies from the expected portion, and as the "rule of thumb" the used limit is 1.96. Consequently, if the empirical z-values are greater than the critical value of 1.96 ( $\alpha=5$ percent), this indicates the possibility of an accounting fraud.

The general formula for the Z-test (proportion test) is:

$$
z=\frac{p_{0}-p_{1}}{\sqrt{\frac{p_{1} \cdot\left(1-p_{1}\right)}{n}}}
$$

where $p_{0}$ is the expected proportion, $p_{1}$ is the obtained proportion, and $n$ is the sample size. 
This formula was adapted for the continuity correction factor (Nigrini, 1996):

$z=\frac{\left|p_{0}-p_{1}\right|-\frac{1}{2 \cdot n}}{\sqrt{\frac{p_{1} \cdot\left(1-p_{1}\right)}{n}}}$.

However, the Z-test "suffers" from excessive statistical problems, i.e., it shows large significant differences for large data collections even if the differences are quite small (Miller \& Nigrini, 2008). Therefore, this test becomes more sensitive to deviations as observations increase.

To overcome this phenomenon, the mean absolute deviation (MAD) measure is recommended. MAD takes into account the absolute value of the difference between the proportions, regardless of whether the value is positive or negative. If the mean absolute deviation is larger, the average difference will be larger, with the caveat that MAD does not generate objective critical results necessary for decision-making.

$M A D=\frac{\sum_{i=1}^{d}\left|p_{0}-p_{1}\right|}{d}$.

Drake and Nigrini (2000) offered some guidelines to determine critical scores and ranges for testing compliance with Benford's law.

Table 2: Critical Values and Conclusions for MAD Values

\begin{tabular}{l|c|c}
\hline Digit & Rank & Conformity \\
\hline First digit & $0.000-0.006$ & High \\
& $0.006-0.012$ & Acceptable \\
& $0.012-0.015$ & Marginally acceptable \\
& Above 0.015 & Unacceptable \\
\hline First two digits & $0.0000-0.0012$ & High \\
\hdashline & $0.0012-0.0018$ & Acceptable \\
\hline & $0.0018-0.0022$ & Marginally acceptable \\
& Above 0.0022 & Unacceptable \\
\hline
\end{tabular}

Source: Drake and Nigrini (2000). 
The chi-square $\left(\chi^{2}\right)$ test observes the obtained and expected data frequencies, and the formula is:

$\chi^{2}=\sum_{i=1}^{9} \frac{\left(C_{i}-O_{i}\right)^{2}}{O_{i}}$,

where $C_{i}$ is the obtained digit frequency and $O_{i}$ is the expected digit frequency.

The obtained result of the chi-square test is compared with the critical value with the selected level of significance. The disadvantage of the chi-square test is that conclusions are based on a small sample, i.e., the test is not considered useful in the case of a small sample.

The K-S test (Kolmogorov-Smirnov test) is based on the calculation of the maximum deviation from the distribution according to Benford's law. The formula is as follows:

$$
K-S=\max \left\{\left|C_{1}-O_{1}\right|, \ldots\left|\left(C_{1}+C_{2}+\cdots+C_{9}\right)-\left(O_{1}+O_{2}+\cdots+O_{9}\right)\right|\right\} .
$$

The obtained value of the K-S test is compared with the critical value, which is calculated as follows (significance level 95 percent):

$p=\frac{1.36}{\sqrt{n}}$.

Nigrini (2011) identified through a series of studies the recommended critical values of the tests that will be used for drawing the conclusion. The values are given in Table 3.

Table 3: Recommended Critical Values of Statistical Tests

\begin{tabular}{l|c|c}
\hline Test & First digit & First two digits \\
\hline MAD & 0.015 & 0.0022 \\
\hline Z-test & 1.96 & 1.96 \\
\hline Chi-square & 15.51 & 112.02 \\
K-S test & $0.0393(\mathrm{P})$ & $0.0401(\mathrm{P})$ \\
& $0.0331(\mathrm{R})$ & $0.0333(\mathrm{R})$ \\
\hline
\end{tabular}

Source: Authors' calculations based on Nigrini (2011). 
In general, the well-known standpoint is that the results of Benford's analysis are more reliable if the entire population is analyzed as opposed to sampling, because if there is a larger number of transactions or items in the data collection, the analysis is considered more truthful (Durtschi et al., 2004).

In order for the accounting data collection to follow Benford's law, it is necessary that the arithmetic mean is greater than the median, and that there is positive asymmetry. Further, the higher the mean-to-median ratio, the closer the accounting data collection is to Benford's distribution (Wallace, 2002).

\section{Results of Empirical Research: Benford's Law in Forensic Analysis of Income Statements of Economic Entities in BiH}

The issue of detecting fraud in financial statements has captured the attention of many authors, and empirical research has identified fraud in the field of earnings management as the most commonly committed fraud through financial statements (Schilit \& Perler, 2010). Therefore, revenue and expense manipulations are a top priority for forensic accountant investigations. Boyle (1994) confirmed through research that the distribution of data resulting from the mathematical product of random variables taken from divergent sources such as revenues (e.g., sales as a product of selling price and quantity) and expenses (e.g., costs of goods sold as a product of cost price and quantity) follows the Benford distribution. This means that the application of Benford's law on aggregate revenues and expenses of entities in $\mathrm{BiH}$ can provide forensic accountants with information on potential earnings manipulation. Thus, we consider it acceptable to submit the items of revenues and expenses presented in the income statements of $\mathrm{BiH}$ entities to forensic analysis by applying the methodology of Benford's law.

According to Nigrini (2011), the conditions for the application of Benford's law are an arithmetic mean greater than the median and positive asymmetry. The recommendation is a sample of a minimum of 1,000 records. 
Due to limited access to financial statements of all/many entities in $\mathrm{BiH}$, because the financial reporting of entities in $\mathrm{BiH}$ in general is characterized by nontransparency, the financial statements of entities listed on the Sarajevo Stock Exchange $^{1}$ were used for the empirical research. The sample includes all entities listed on the Sarajevo Stock Exchange that published financial statements for 2018, i.e., 1,197 revenue positions and 1,686 expense positions in the income statements for 2018 of 166 business entities, thus sufficiently fulfilling the condition for the application of Benford's law on the financial statements of entities. The data were processed using Excel and SPSS (Statistical Package for the Social Sciences).

Descriptive statistics for the variables revenues and expenses are presented in Table 4.

Table 4: Descriptive Statistics for the Variables Revenues and Expenses

\begin{tabular}{|c|c|c|c|}
\hline Descriptive statistics & Condition & Revenues & Expenses \\
\hline $\mathrm{N}$ & $>1,000$ & 1,197 & 1,686 \\
\hline Mean & $>$ Median & $3,603,701.35$ BAM & $2,752,306.3$ BAM \\
\hline Median & & 36,165 BAM & 71,671.5 BAM \\
\hline Mode & & $1 \mathrm{BAM}$ & $1 \mathrm{BAM}$ \\
\hline Std. deviation & & $35,144,514.23$ BAM & $19,504,467.79$ BAM \\
\hline Skewness & $>0$ & 22.249 & 16.656 \\
\hline Std. error of skewness & & 0.071 & 0.06 \\
\hline Kurtosis & & 583.411 & 349.957 \\
\hline Std. error of kurtosis & & 0.141 & 0.119 \\
\hline Minimum & & $1 \mathrm{BAM}$ & $1 \mathrm{BAM}$ \\
\hline Maximum & & $1,006,311,946$ BAM & $488,194,856$ BAM \\
\hline
\end{tabular}

Source: Authors' calculations.

1 Sarajevo Stock Exchange (SASE) was founded in 2001 by eight equal brokerage houses from the Federation of $\mathrm{BiH}$. Trade takes place in the official market and the free market, and the trading algorithms are continuous and auction trading. Currently, SASE has 304 issuers, 283 listed securities, and 5 indices (BIFX is for investment funds, SASX-10 tracks the top 10 issuers, SASX-30 depicts the most liquid issuers on the primary free market, SASX-BBI is based on the top 25 companies that meet the conditions from the Shariah methodology, and SASXFN tracks the top 15 companies on the market according to profit). This information was retrieved from: http:// www.sase.ba/v1 
In Table 4 we can see that the conditions for the application of Benford's law are met; the number of records is 1,197 (revenues) and 1,686 (expenses), the arithmetic means of the variables revenues and expenses are greater than the medians, and the asymmetries are positive.

As Table 4 shows, the average value of revenues reported by entities is 3,603,701.35 $\mathrm{BAM}$, and the average value of expenses is 2,752,306.3 BAM. The medians are significantly smaller than the arithmetic means, which is understandable, given that the income statement presents many positions of the categories of "other income and expenses" that are significantly lower than the positions of operating revenues and expenses. The most frequently presented amount of both revenues and expenses is $1 \mathrm{BAM}^{2}$, which is also the least presented amount, and the largest amount of revenues is over 1 billion BAM. Outliers are not removed because the methodology is not affected by the size of the variable (absolute amount), but only by the first digit (or the first and second digits).

Figure 1: First Digits Expected and Obtained for the Variables Revenues and Expenses

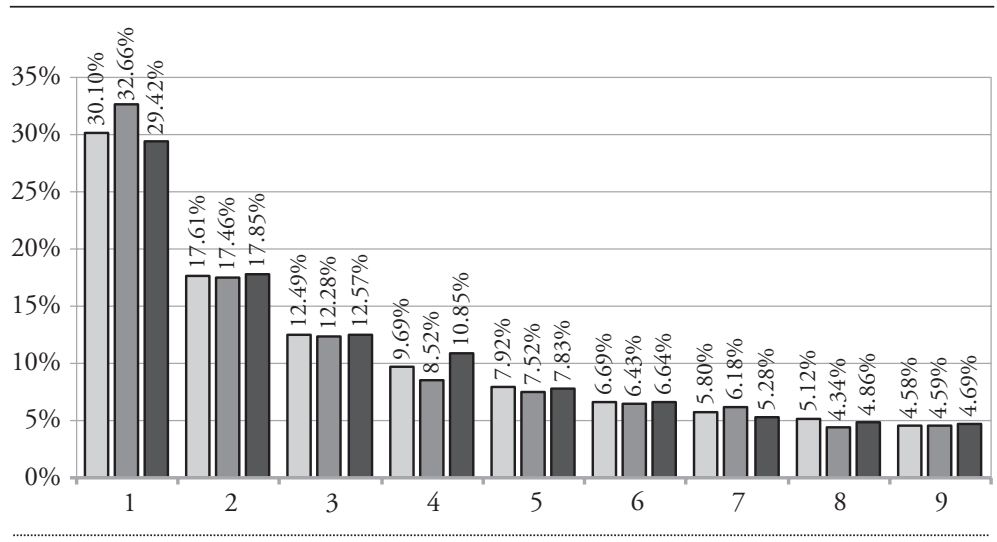

$\square$ Expected \% according to Benford $\square$ Obtained \% revenues

Obtained \% expenses

Source: Authors' calculations.

222 revenue items (or 1.80 percent) and 8 expense items (or 0.50 percent) were presented in the amount of 1 BAM, which is not significant for examination whether the accounting data follow Benford's law. Otherwise, a significant frequency of one digit (in this case 1 BAM) would show data deviation in statistical tests. 
Table 5: Overview of Statistical Tests for the Variables Revenues and Expenses - First Digit

\begin{tabular}{l|c|c|c}
\hline Test & $\begin{array}{c}\text { Obtained value } \\
\text { Revenues }\end{array}$ & $\begin{array}{c}\text { Obtained value } \\
\text { Expenses }\end{array}$ & $\begin{array}{c}\text { Critical value according } \\
\text { to Nigrini (2011) }\end{array}$ \\
\hline MAD & 0.0038 & 0.0024 & 0.015 \\
\hline Z-test & $-0.03-1.86$ & $0.04-1.49$ & 1.96 \\
\hline Chi-square & 6.4171 & 3.7456 & 15.51 \\
K-S test & $-0.026-0$ & $-0.008-0$ & 0.0393 (revenues) \\
\hline
\end{tabular}

Source: Authors' calculations.

Table 5 provides an overview of the results of testing the data distribution of the variables revenues and expenses according to the four statistical tests from the research conceptual framework and according to recommended critical values by Nigrini (2011). Expected and obtained distributions are shown in Figure 1 (see also Tables A1 and A2 in the Appendix, where the statistical tests for the variables revenues and expenses are presented).

Based on the conducted tests, we can conclude that none of the tests show a significant deviation of the data distribution for the variables revenues and expenses - the first digit - when compared to Benford's data distribution.

Additionally, we can observe that the results of each test for the variable expenses are further away from the critical values in relation to the variable revenues, which implies that there is a lower probability of fraud in expenses in relation to revenues (the variable expenses follows Benford's distribution to a greater degree than the variable revenues).

According to the same research framework, testing of data distribution of the first two digits for the variables revenues and expenses was performed, and an overview of the results is presented in Table 6 (Tables A3 and A4 in the Appendix contain the tests for the variables revenues and expenses - first two digits). 
Table 6: Overview of Statistical Tests for the Variables Revenues and Expenses - First Two Digits

\begin{tabular}{l|c|c|c}
\hline Test & $\begin{array}{c}\text { Obtained value } \\
\text { Revenues }\end{array}$ & $\begin{array}{c}\text { Obtained value } \\
\text { Expenses }\end{array}$ & $\begin{array}{c}\text { Critical value according } \\
\text { to Nigrini (2011) }\end{array}$ \\
\hline MAD & 0.0019 & 0.0015 & 0.022 \\
\hline Z-test & $-0.18-7.50$ & $-0.06-2.93$ & 1.96 \\
Chi-square & 85.11 & 77.91 & 112.02 \\
K-S test & $-0.03-0$ & $-0.009-0$ & 0.0401 (revenues) \\
\end{tabular}

Source: Authors' calculations.

Figure 2: First Two Digits With a Statistically Significant Difference for the Variable Revenues

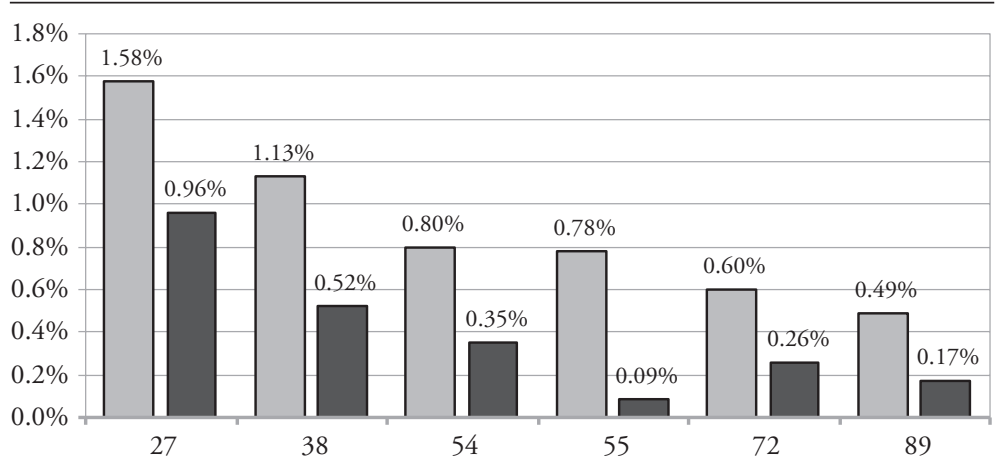

Expected \% according to Benford

Obtained \%

Source: Authors' calculations.

According to the Z-test, there is a statistically significant difference between the expected and obtained distribution for the following first two digits in the amounts of revenues: $27(\mathrm{z}=2.02), 38(\mathrm{z}=2.65), 54(\mathrm{z}=2.34), 55(\mathrm{z}=7.50)$, and $89(\mathrm{z}=2.18)$, while the number 72 is on the critical value $(z=1.96)$. Other tests do not show a statistically significant deviation from the theoretical distribution according to Benford. Figure 2 shows the expected and obtained percentage of the first two digits for revenues with a statistically significant difference, according to the Z-test. 
Figure 3: First Two Digits With a Statistically Significant Difference for the Variable Expenses

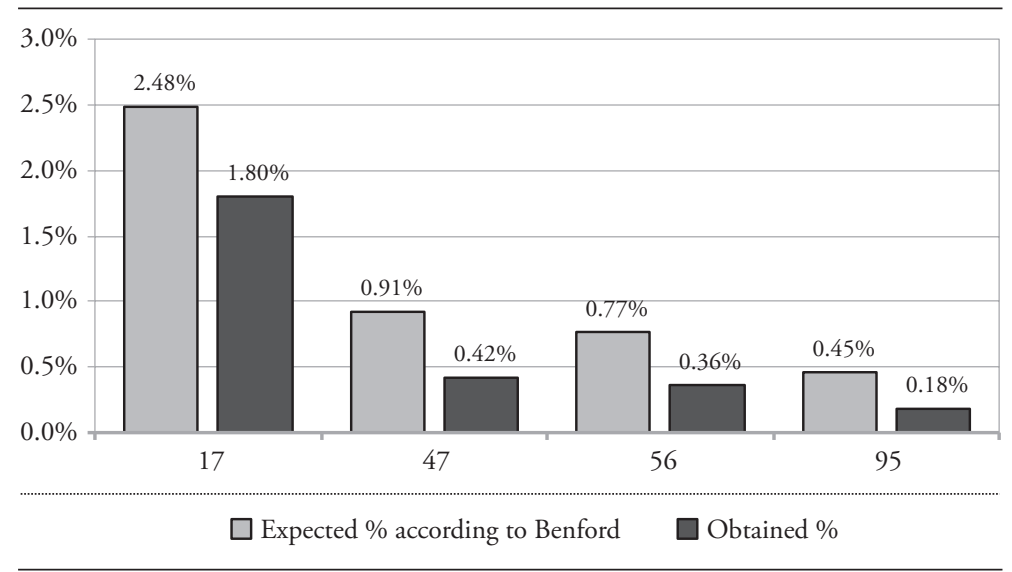

Source: Authors' calculations.

According to the Z-test, there is a statistically significant difference between the expected and obtained distribution for the following first two digits of the variable expenses: $17(\mathrm{z}=2.00), 47(\mathrm{z}=2.93), 56(\mathrm{z}=2.58)$, and $95(\mathrm{z}=2.35)$. Other tests do not show significant differences between the obtained results and the expected distributions according to Benford's law. Figure 3 shows the expected and obtained percentage of the digits for the variable expenses with a statistically significant difference, according to the Z-test.

For the purpose of testing the hypothesis of the existence of statistically significant differences in the distribution of the first digit between the positions of revenues and expenses, we used the Z-test. The results are presented in Table 7. 
Table 7: Test Results of the Existence of Differences Between Revenues and Expenses

\begin{tabular}{|c|c|c|c|c|c|}
\hline Digit & $\begin{array}{c}\text { Frequency } \\
\text { Revenues }\end{array}$ & $\begin{array}{c}\text { Frequency } \\
\text { Expenses }\end{array}$ & $\begin{array}{c}\% \\
\text { Revenues }\end{array}$ & $\begin{array}{c}\% \\
\text { Expenses }\end{array}$ & Z-test \\
\hline 1 & 391 & 496 & 0.3266 & 0.2942 & 2.36 \\
\hline 2 & 209 & 301 & 0.1746 & 0.1785 & 0.32 \\
\hline 3 & 147 & 212 & 0.1228 & 0.1257 & 0.27 \\
\hline 4 & 102 & 183 & 0.0852 & 0.1085 & 2.84 \\
\hline 5 & 90 & 132 & 0.0752 & 0.0783 & 0.35 \\
\hline 6 & 77 & 112 & 0.0643 & 0.0664 & 0.24 \\
\hline 7 & 74 & 89 & 0.0618 & 0.0528 & 1.24 \\
\hline 8 & 52 & 82 & 0.0434 & 0.0486 & 0.81 \\
\hline 9 & 55 & 79 & 0.0459 & 0.0469 & 0.08 \\
\hline
\end{tabular}

Source: Authors' calculations.

As we can see from Table 7, for figures 1 and 4, there is a statistically significant difference in distribution between the variable revenues and the variable expenses $(z=2.36$ and $z=2.84$, which is greater than the threshold 1.96).

The first research hypothesis was:

H1: The items of revenues and expenses shown in the income statements of economic entities in BiH follow Benford's law.

This hypothesis can be divided into two sub-hypotheses:

H1.1: The first digit of the amounts of revenues and expenses shown in the income statements of economic entities in BiH follows Benford's law.

H1.2: The first two digits of the amounts of revenues and expenses shown in the income statements of economic entities in BiH follow Benford's law.

For hypothesis H1.1, none of the tests show a statistically significant deviation from the Benford distribution. Therefore, we can accept the hypothesis that the first digit of the amounts of revenues and expenses presented in the income statements of economic entities in $\mathrm{BiH}$ follows Benford's law. 
For hypothesis H1.2, the Z-test shows a statistically significant difference for the following digits of the variable revenues: $27(\mathrm{z}=2.02), 38(\mathrm{z}=2.65), 54(\mathrm{z}=$ 2.34), $55(\mathrm{z}=7.50), 89(\mathrm{z}=2.18)$, and $72(\mathrm{z}=1.96)$, and for the following digits of the variable expenses: $17(\mathrm{z}=2.00), 47(\mathrm{z}=2.93), 56(\mathrm{z}=2.58)$, and $95(\mathrm{z}=$ 2.35). For the remaining 170 two-digit items of revenues and expenses, there is no statistically significant difference from the Benford distribution. Therefore, we can partially, for the above presented figures, reject the hypothesis that the first two digits of the amounts of revenues and expenses stated in the income statements of economic entities in BiH follow Benford's law. This is also an indicator - a red flag to forensic accountants of the necessity of increased attention and additional examination of the financial positions of revenues and expenses starting with the identified first two digits.

The results of the conducted empirical research, which show a higher frequency of deviations of the distribution of the first two digits in the presentation of revenue positions ( 6 figures) compared to the distribution of the first two digits in the presentation of expense items (4 figures), correspond to previous empirical research, which indicated more frequent manipulation of revenues than expenses, both quantitatively and qualitatively. Namely, among the so-called "seven deadly sins in accounting", four sins were related to revenues and three sins were related to expenses; moreover, the first three sins according to the frequency of occurrence were related to the manipulation of revenues in entities' financial statements (Schilit \& Perler, 2010). Additionally, research on the application of creative accounting techniques in entities in $\mathrm{BiH}$ has shown that revenue manipulation, specifically the technique of recording revenue too soon, is the most commonly used technique of manipulating accounting data presented in financial statements in entities in $\mathrm{BiH}$ (Isaković-Kaplan, 2016).

However, we warn readers of the risk of "blindly believing" in Benford's law, i.e., the results of the application of the methodology of Benford's law should serve only as a guide to the forensic accountant in further examination of information and evidence regarding frauds committed in entities, and not as proof that 
frauds were committed exactly on the identified items of revenues and expenses whose first digits deviate from Benford's law. Also, the absence of a large number of deviations in the digits of revenue and expense positions in relation to the distribution of data according to Benford's law is not a guarantee of the absence of frauds in the financial statements of entities in $\mathrm{BiH}$.

The second research hypothesis was:

H2: There is no statistically significant difference in the distribution of the first digit between the items of revenues and expenses shown in the income statements of economic entities in $\mathrm{BiH}$.

Based on the conducted Z-test, we can see that there is no statistically significant difference for seven digits, while for digits 1 and 4 there is a statistically significant difference (for digit 1 the $\mathrm{z}$-score is $2.36>1.96$, and for digit 4 the $\mathrm{z}$-score is 2.84 $>1.96)$. Therefore, we partially, for these two digits, reject the hypothesis that there is no statistically significant difference in the distribution of the first digit between the items of revenues and expenses presented in the income statements of economic entities in $\mathrm{BiH}$.

It is interesting to compare the results of this empirical research with the results of empirical research conducted in the region.

Papić et al. (2017) conducted a research on 12 entities listed on the Zagreb Stock Exchange covering all positions in the financial statements over 10 years and concluded that all 12 entities recorded deviations from Benford's distribution, but there was a noticeable trend towards Benford's law.

Kovačić and Mateješ (2018) applied Benford's law to insurance entities in Croatia and showed that revenue positions, both the first and second figures, actually followed Benford's distribution.

Bartulović and Mitrović (2020) investigated the application of Benford's law on the accounts receivable and accounts payable of an entity in Croatia operating in 
the tourism business. The results of the research showed that there were smaller deviations from Benford's law, where the deviations were larger in accounts payable than in accounts receivable.

Milojević et al. (2014) investigated the application of Benford's law in detecting anomalies in financial statements on a sample of 814 large entities in Serbia by analyzing fixed asset positions in balance sheets and net profit positions in income statements. The research showed that all first digits of presented fixed asset positions followed Benford's law, while the distribution of the first digit of the net profits of large entities in Serbia did not fully follow Benford's law. The digits that were not in line with Benford's law were 1, 8 , and 9, with a high frequency of digits 1 and 9, and a low frequency of the figure 8 as the first digit in presented net profits.

It is important to know that the results of applying the methodology of Benford's law are not used only by forensic accountants in forensic accounting. Various analyses based on the phenomenon of the first digit are useful to many external users of financial statements, among which we especially emphasize financial analysts, but also investors, creditors, and government agencies that can conduct various analyses of data quality presented in financial statements for their own needs. The methodology of Benford's law is a useful tool for auditors in the process of financial statement audit.

The application of Benford's law on a sample of many entities provides useful information on the potential risks of manipulative accounting at the level of an economy, while its application on data within an entity is a useful tool for forensic accountants in conducting individual fraud investigations. At the same time, the application of Benford's law within an entity is possible on different sets of accounting data that are derived as a result of mathematical operations on certain basic values. Accordingly, in addition to the items of revenues and expenses analyzed in this paper, accounts receivable, accounts payable, material costs, salary costs, etc. can be submitted to forensic analysis according to the same methodology. 
After the application of Benford's law indicates certain discrepancies in the data presented in the entity's financial statements, in relation to the expected values, the forensic accountant should focus further investigation on the forensic analysis of the entire accounting records in relation to the disputed accounting data, i.e., accounting entries/postings that are behind the disputed positions, together with the documentation that served as the basis for the book entries in the accounting records (Isaković-Kaplan, 2016).

\section{Concluding Considerations}

The application of Benford's law methodology in the investigation of financial statement fraud helps forensic accountants to more quickly and easily identify the distribution of data that does not follow the phenomenon of the first digit.

The empirical research of this paper was based on the financial statements of listed economic entities in $\mathrm{BiH}$. The sample included all entities listed on the Sarajevo Stock Exchange that published annual financial reports for 2018, and the analysis included the positions of revenues and expenses presented in them.

The research showed that the presented values of revenues and expenses of economic entities in $\mathrm{BiH}$ generally follow Benford's law. The exceptions are 10 figures from 180 two-digit numbers which, according to the Z-test, show statistically significant deviations from the expected distribution. In addition, there is a statistically significant difference in the distribution of digits 1 and 4 between revenues and expenses.

In this way, this research confirms that accounting data of entities in $\mathrm{BiH}$ follow the phenomenon of the first digit, which is additional empirical proof of the applicability of Benford's law to accounting data collections. Also, the contribution of this paper is reflected in the fact that it can serve as a guide for forensic accountants and auditors in their daily work with large sets of accounting data. 
Restrictions in the application of Benford's law in detecting fraud in financial statements appear in the case of deliberate action of the perpetrator of fraud in accordance with the phenomenon of the first digit in terms of choosing the amounts which he/she wants to include in the set, modify, or exclude from the set of accounting data. Simplified, deviations from the phenomenon of the first digit can be more easily determined if the perpetrator is not familiar with the nature of the occurrence of the digits, because such manipulation is likely to result in a significant deviation of the data from the distribution under Benford's law. If the perpetrator knows the expected distribution, he/she will manipulate the data by adjusting the frequencies of the numbers, which will not ultimately result in a significant deviation from the distribution according to Benford's law.

Significant deviations from Benford's law indicate that the sets of accounting data were subjected to manipulation. This information can serve only as an indicator to forensic accountants in their further search for illogical distributions, but not as a basis for concluding that fraud has occurred in the entity. The same information can offer support and guidance to the auditors in their further search for additional information in the audit of financial statements.

Since the conducted research included entities listed on the Sarajevo Stock Exchange, this fact can be considered a restriction of the paper. If access could be gained to the register of financial statements of all entities, a research could be conducted covering all entities in $\mathrm{BiH}$. Furthermore, research could be conducted for the financial sector, as well as for the non-profit sector in $\mathrm{BiH}$.

Additionally, analyzing the application of Benford's law over several periods is interesting from the point of view of observing the distribution of data by years and testing statistical significance differences between the years, but it is not appropriate if all data are analyzed together. This can also represent an opportunity for research. 


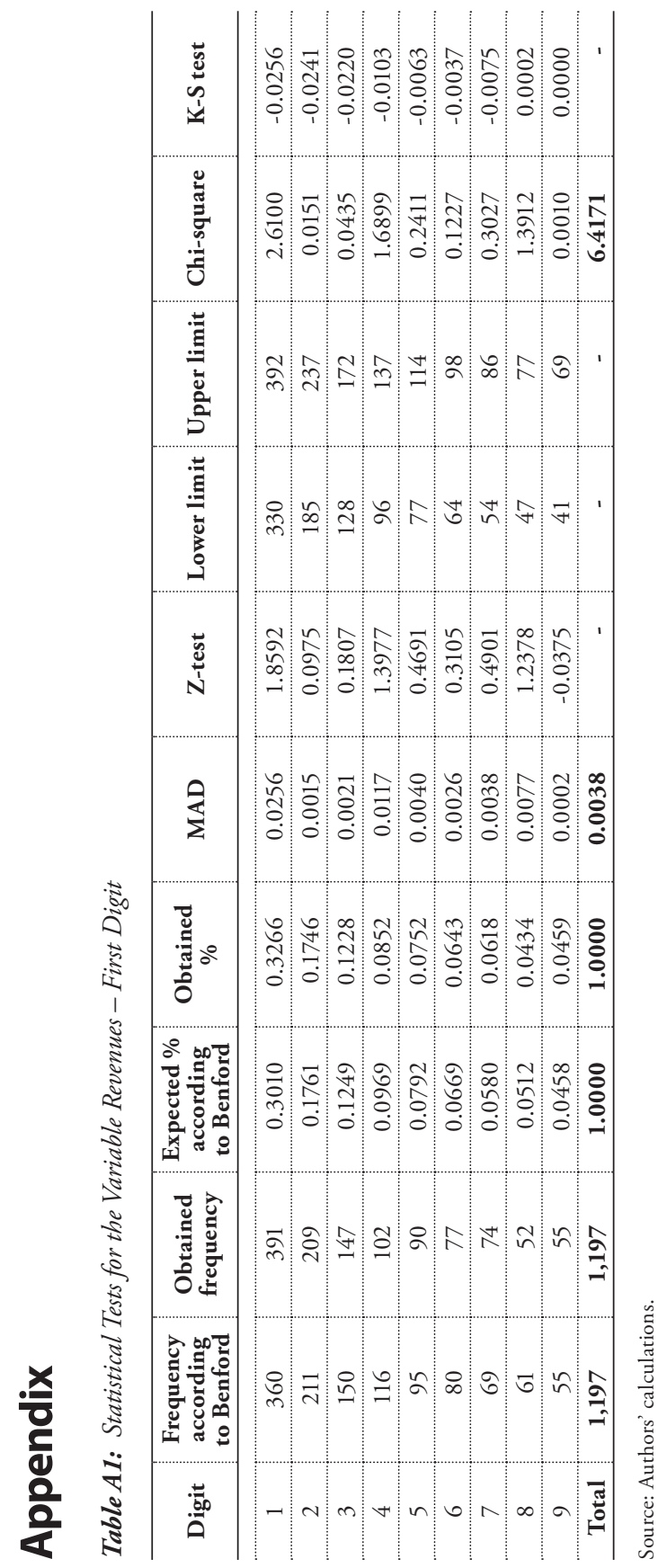




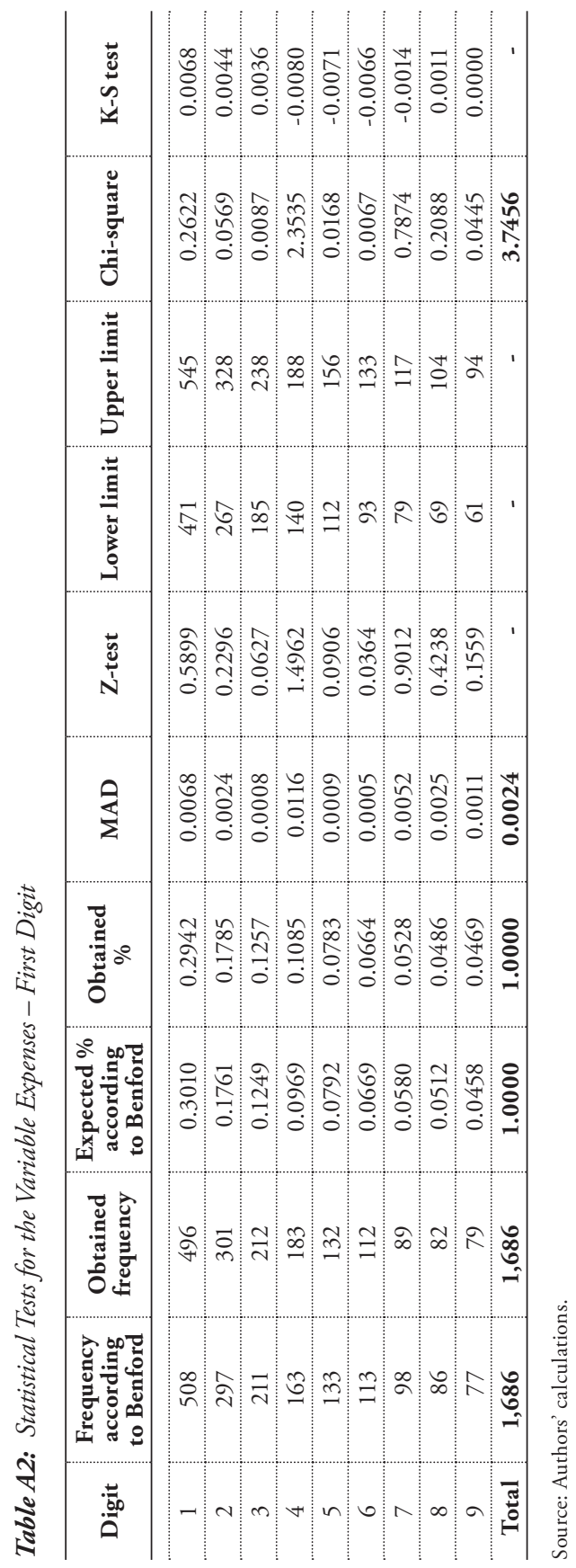




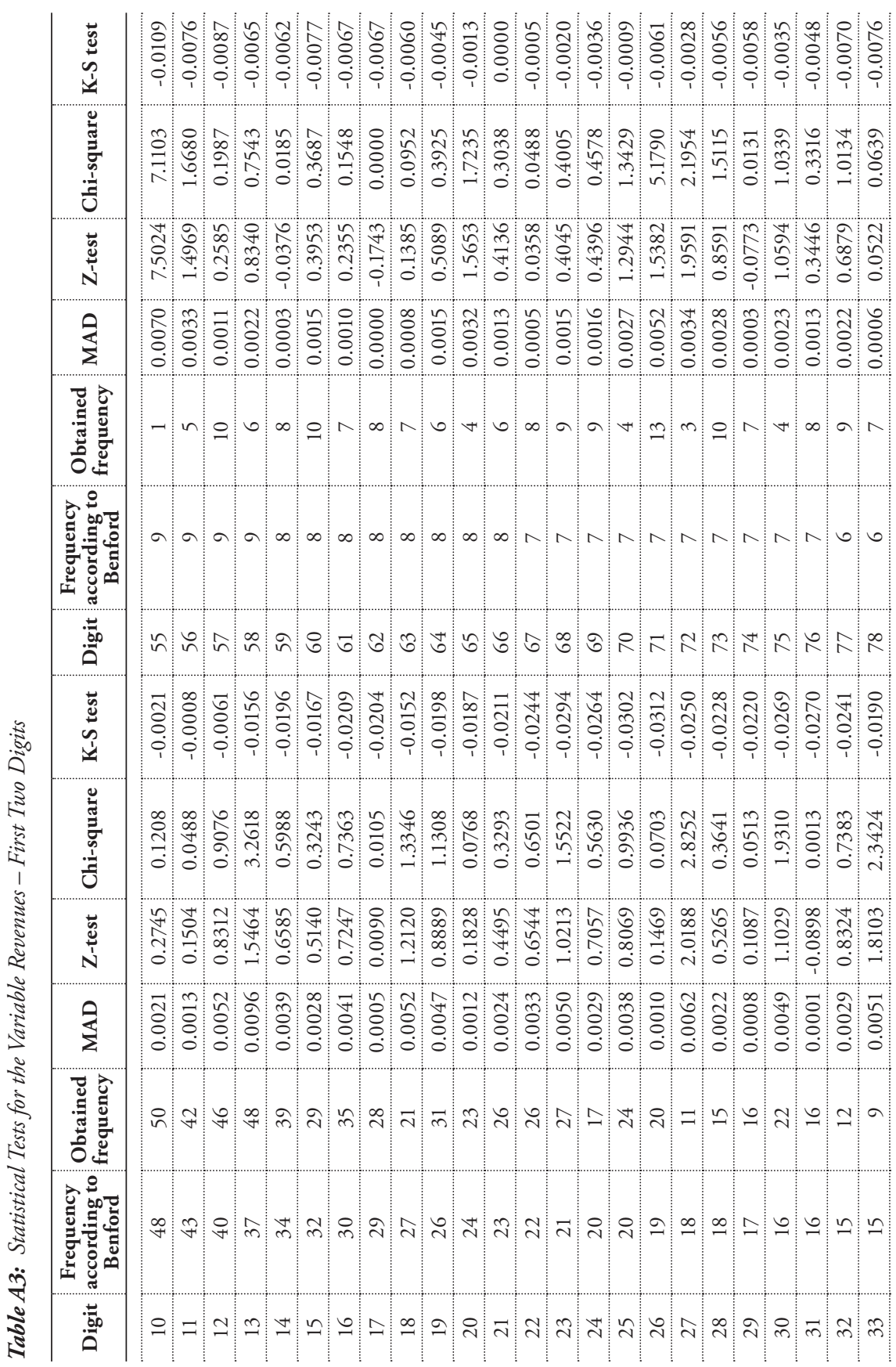




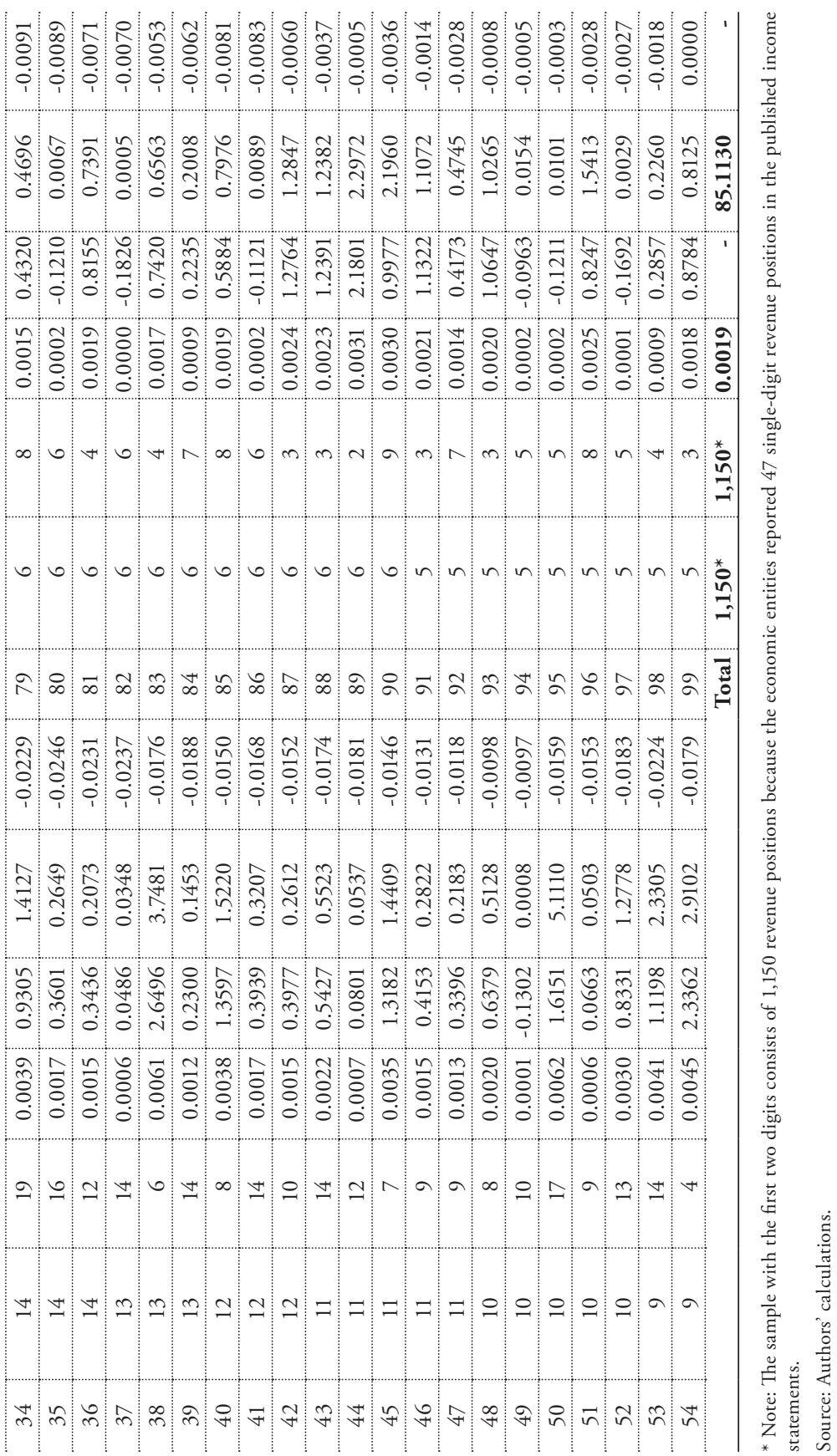




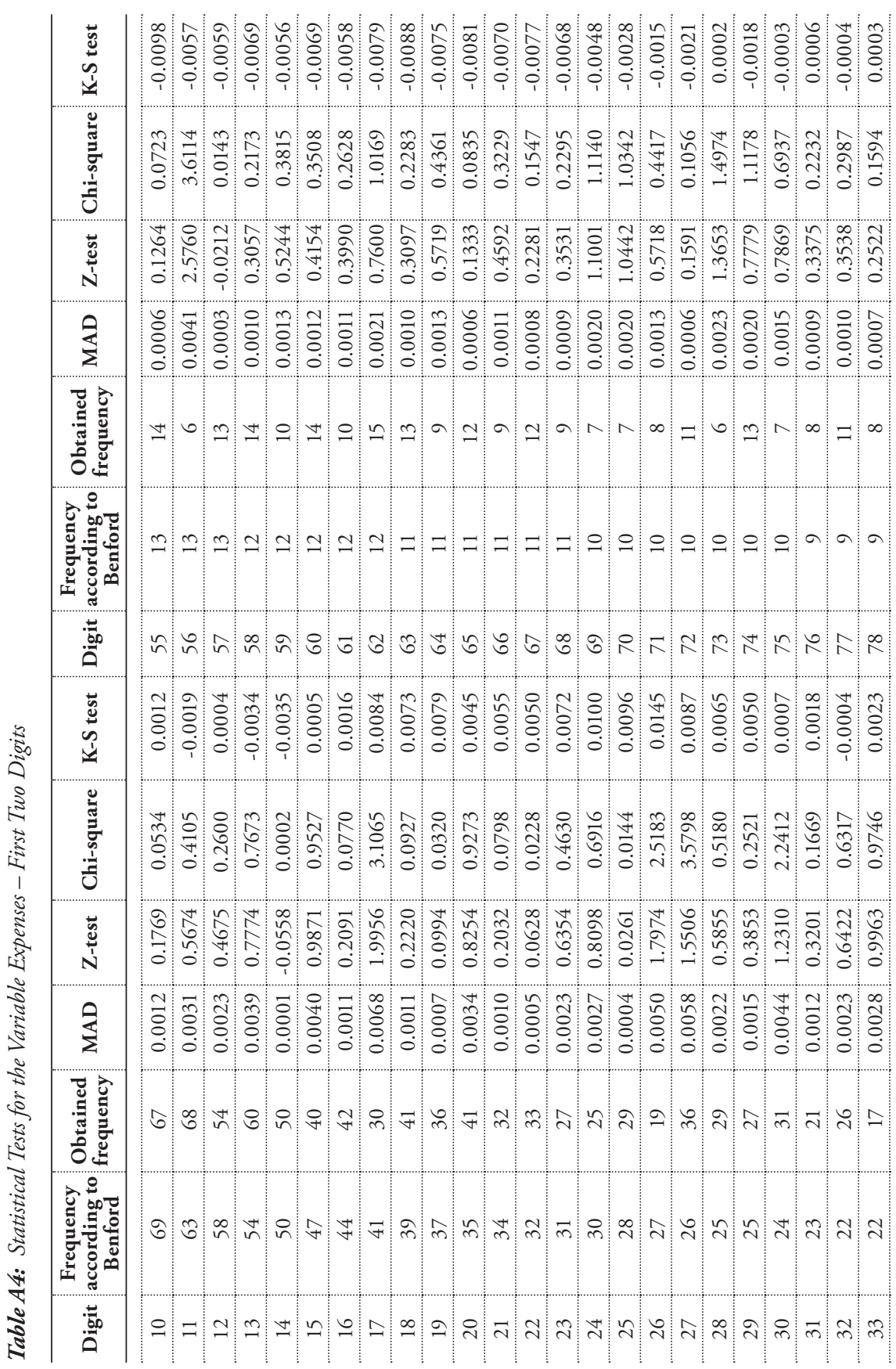




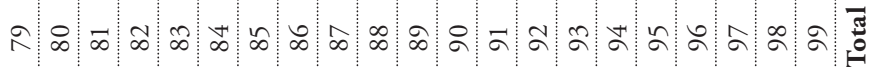

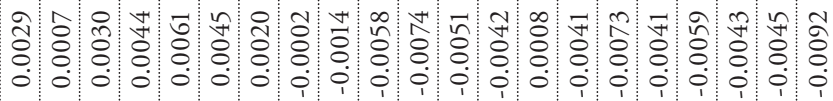

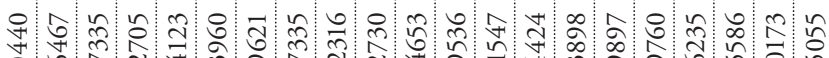

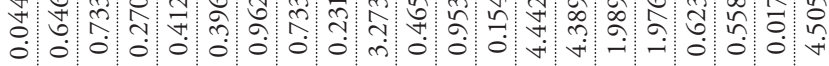

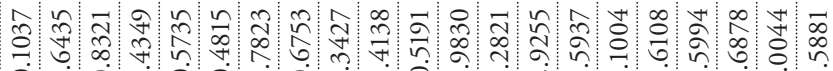

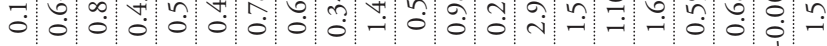

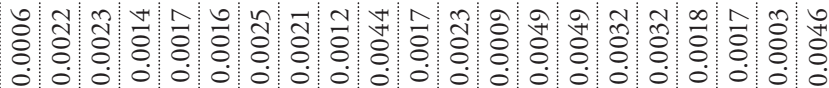

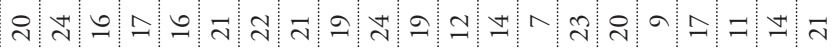

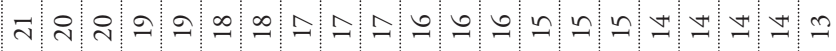
m m m

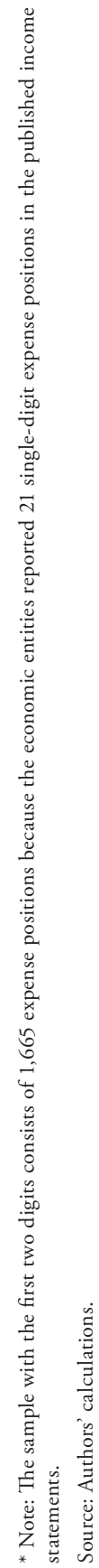




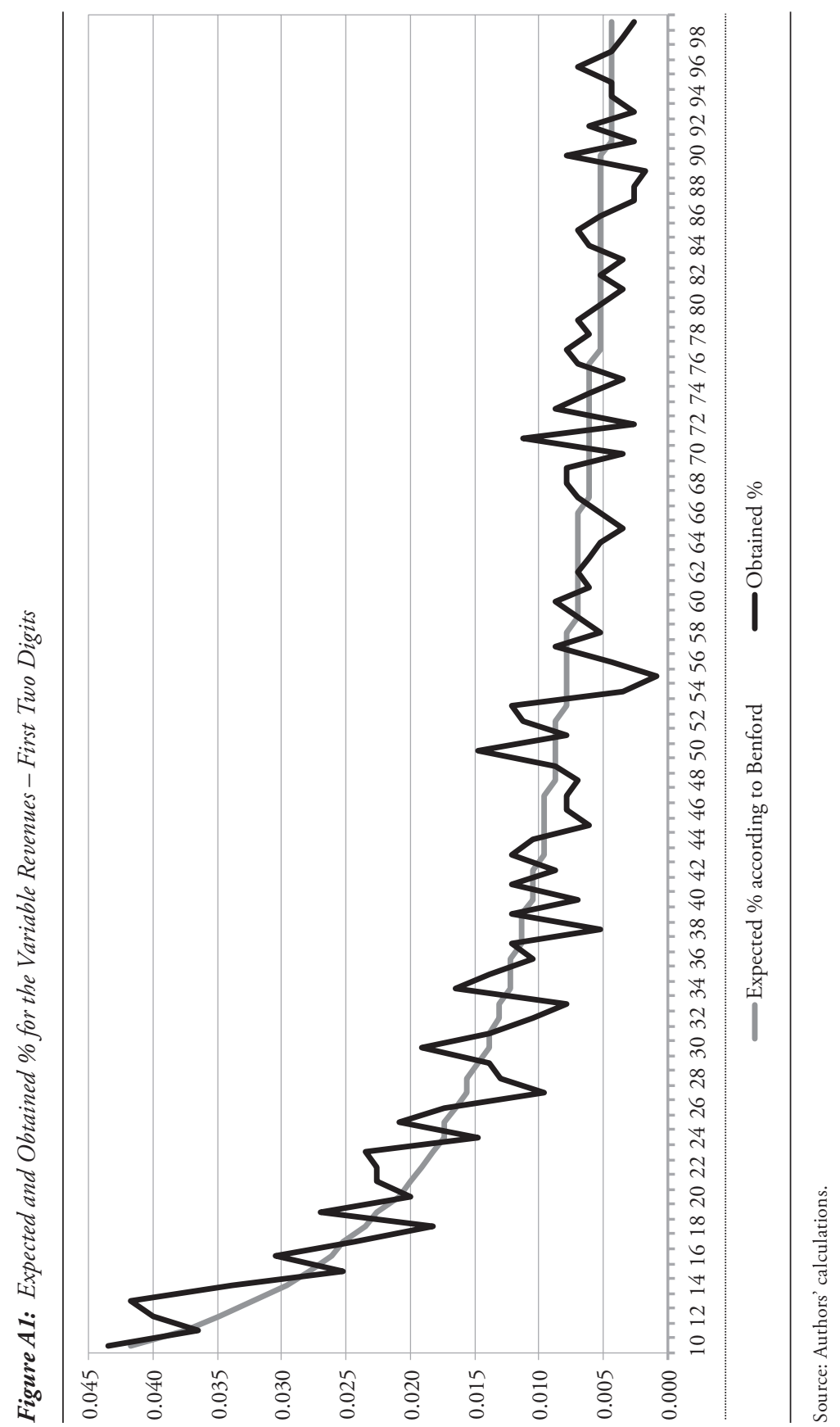




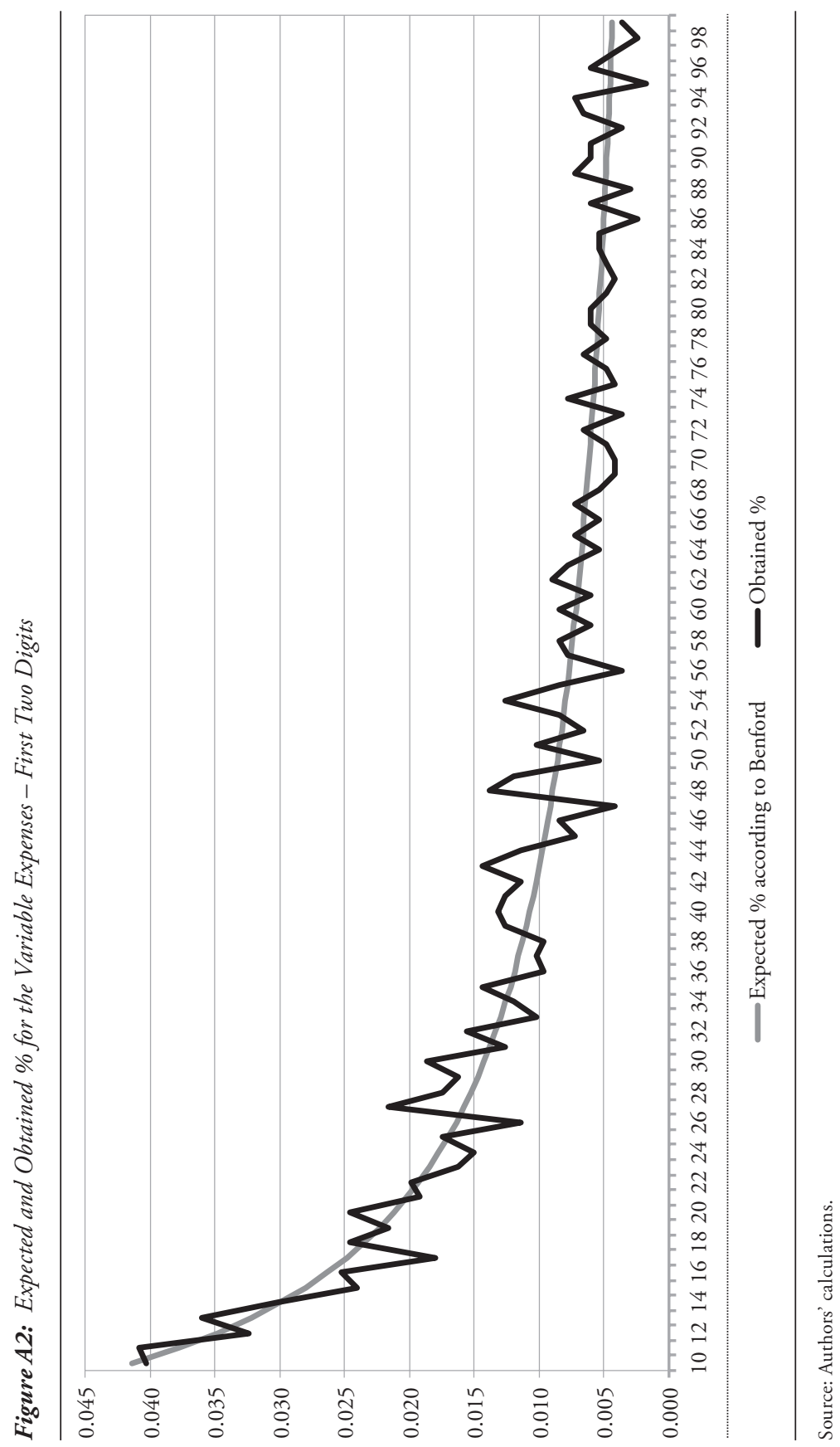




\section{Literature}

Bartulović, M., \& Mitrović, M. (2020). Application of Benford's law in forensic accounting. Conference Proceedings, International Scientific \& Professional Conference Contemporary Issues in Economy \& Technology, CIET 2020, Split (pp. 384-391).

Benford, F. (1938). The law of anomalous numbers. Proceedings of the American Philosophical Society, 78(4), 551-572.

Boyle, J. (1994). An application of Fourier series to the most significant digit problem. American Mathematical Monthly, 101(9), 879-886.

doi: https://doi.org/10.1080/00029890.1994.11997041

Carslaw, C. (1988). Anomalies in income numbers: Evidence of goal oriented behaviour. The Accounting Review, 63(2), 321-327.

Coderre, D. (2000). Computer assisted fraud detection. The Internal Auditor, 57(4), 25-27.

Drake, P., \& Nigrini, M. (2000). Computer assisted analytical procedures using Benford's law. Journal of Accounting Education, 18(2), 127-146.

doi: https://doi.org/10.1016/S0748-5751(00)00008-7

Durtschi, C., Hillison, W., \& Pacini, C. (2004). The effective use of Benford's law to assist in detecting fraud in accounting data. Journal of Forensic Accounting, 5, 17-34.

Hill, T. (1995). A statistical derivation of the significant-digit law. Statistical Science, 10(4), 354-363. doi: https://doi.org/10.1214/ss/1177009869

Isaković-Kaplan, Š. (2016). Forenzično računovodstvo. Fojnica: Štamparija Fojnica.

Kovačić, M., \& Mateješ, J. (2018). Benfordov zakon kao kontrolni mehanizam u računovodstvu i reviziji. Zbornik Ekonomskog fakulteta u Zagrebu, 16(2), 1-19. doi: https://doi.org/10.22598/zefzg.2018.2.1

Lolbert, T. (2006). Digital analysis: Theory and applications in auditing. Hungarian Statistic Review, 84(10), 148-170.

Miller, S., \& Nigrini, M., (2008). The modulo 1 central limit theorem and Benford's law for products. International Journal of Algebra, 2(3), 119-130. 
Milojević, M., Terzić, I., \& Marjanović, V. (2014). Primena Benfordovog zakona u otkrivanju anomalija u finansijskim izveštajima - slučaj velikih preduzeća u Srbiji. Sinteza 2014 - Singidunum University International Scientific Conference: Impact of Internet on Business Activities in Serbia and Worldwide (pp. 564-570).

Newcomb, S. (1881). Note on the frequency of use of the different digits in natural numbers. American Journal of Mathematics, 4(1), 39-40.

doi: https://doi.org/10.2307/2369148

Nigrini, M. (1996). A taxpayer compliance application of Benford's law. The Journal of the American Taxation Association, 18(1), 72-91.

Nigrini, M. (1999). Adding value with digital analysis. The Internal Auditor, 56(1), 21-23.

Nigrini, M. (2011). Forensic analytics: Methods and techniques for forensic accounting investigations. Hoboken, NJ: J. Wiley \& Sons.

doi: https://doi.org/10.1002/9781118386798

Nigrini, M., \& Mittermaier, L. (1997). The use of Benford's law as an aid in analytical procedures. Auditing: A Journal of Practice \& Theory, 16(2), 52-67.

Papić, M., Vudrić, N., \& Jerin, K. (2017). Benfordov zakon i njegova primjena u forenzičkom računovodstvu. Zbornik sveučilišta Libertas, 1-2(1-2), 153-172. Retrieved from: https://hrcak.srce.hr/190860

Schilit, H., \& Perler, J. (2010). Financial shenanigans: How to detect accounting gimmicks \& fraud in financial reports. New York, NY: McGraw Hill.

Tapp, D., \& Burg, D. (2001). Using technology to detect fraud. Pennsylvania CPA Journal, 71(4), 20-23.

Thomas, J. (1989). Unusual patterns in reported earnings. The Accounting Review, 64(4), 737-787. Retrieved from: https://www.jstor.org/stable/247861

Wallace, W. (2002). Assessing the quality of data used for benchmarking and decision-making. Journal of Government Financial Management, 51(3), 16-22.

Zimbelman, M., Albrecht, C., Albrecht, W., \& Albrecht, C. (2012). Forensic accounting. South-Western: Cengage Learning.

https://www.worldcat.org/title/forensic-accounting/oclc/751767805? referer=di \&ht=edition 